CASE REPORTS

\title{
Isobutyl cyanoacrylate as a skin adhesive
}

\author{
J. E. Hale \\ F.R.C.S.
}

Surgical Unit, Westminster Hospital, London, S.W.1

IsOBUTYL cyanoacrylate is one of a homologous series of bactericidal liquid monomers which in the presence of small amounts of moisture rapidly polymerize to form a strong adhesive. The cyanoacrylate monomers, especially methyl, have been used in both experimental (Healey, 1962) and clinical surgery (Vasko, 1965) to bind together moist living tissues, for example to seal wounds of the kidney and spleen and also to reinforce suture anastomoses. The recently introduced isobutyl cyanoacrylate (Matsumoto, 1967) is less toxic than the lower homologues and its experimental use as a tissue adhesive has recently been reported (Hale \& Ellis, 1968).

In two patients, one with an ileostomy and the other with a urinary ileal conduit, isobutyl cyanoacrylate was successfully used to fix the ileostomy appliance firmly to the skin and prevent continued leakage of ileal contents.

\section{Case No. 1}

A.J. A male aged 19 years had an emergency colectomy for fulminating ulcerative colitis. The spout ileostomy (Brooke, 1950) unfortunately retracted and all attempts to prevent leakage of ileal contents were unsuccessful. The patient became suicidally depressed. Isobutyl cyanoacrylate was successfully used to fix the disc of the ileostomy appliance to the skin (Fig. 1). Leakage of faeces was immediately eliminated and the appliance was maintained firmly in position for periods of up to 1 week before further applications of adhesive were necessary (Fig. 2).

\section{Case No. 2}

J.A. Male aged 56 had a total cystectomy for carcinoma of the bladder. An ileal conduit was fashioned and the patient was discharged with a wellfitting ileostomy appliance. He was readmitted 3 months later semi-conscious with severe electrolyte imbalance and was found to have developed a fistula due to pressure by the appliance on the undersurface of the ileostomy stoma. Leakage of urine and movement of the appliance were prevented by the use of isobutyl cyanoacrylate as a skin adhesive.

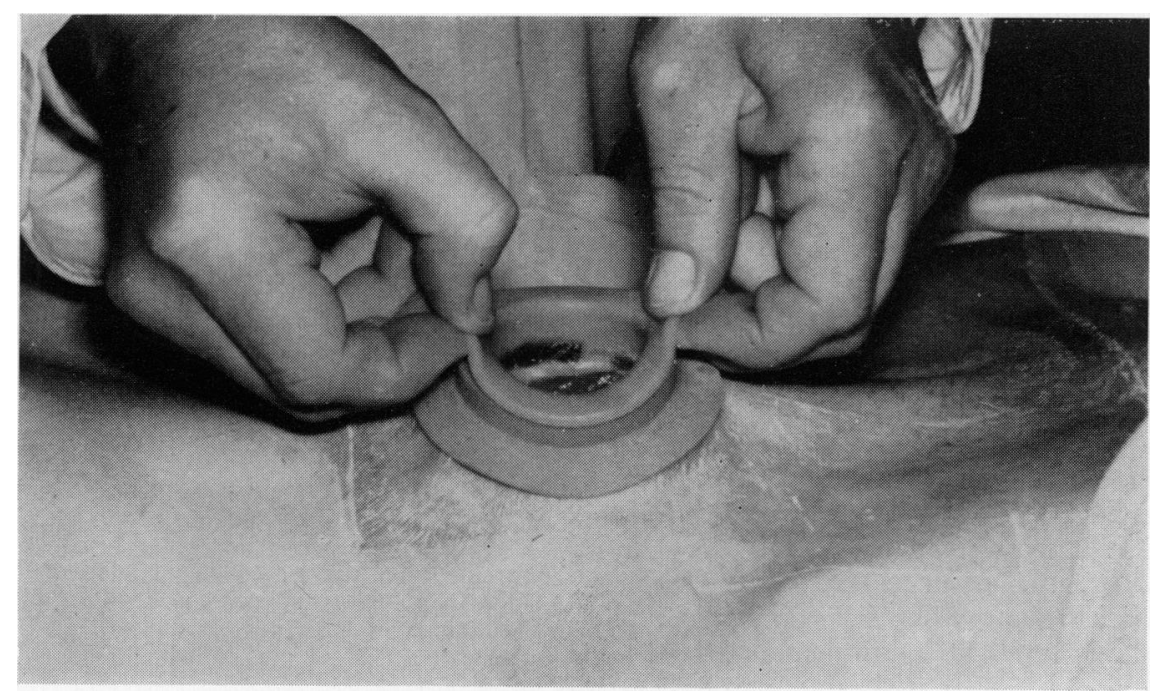

FIG. 1. 


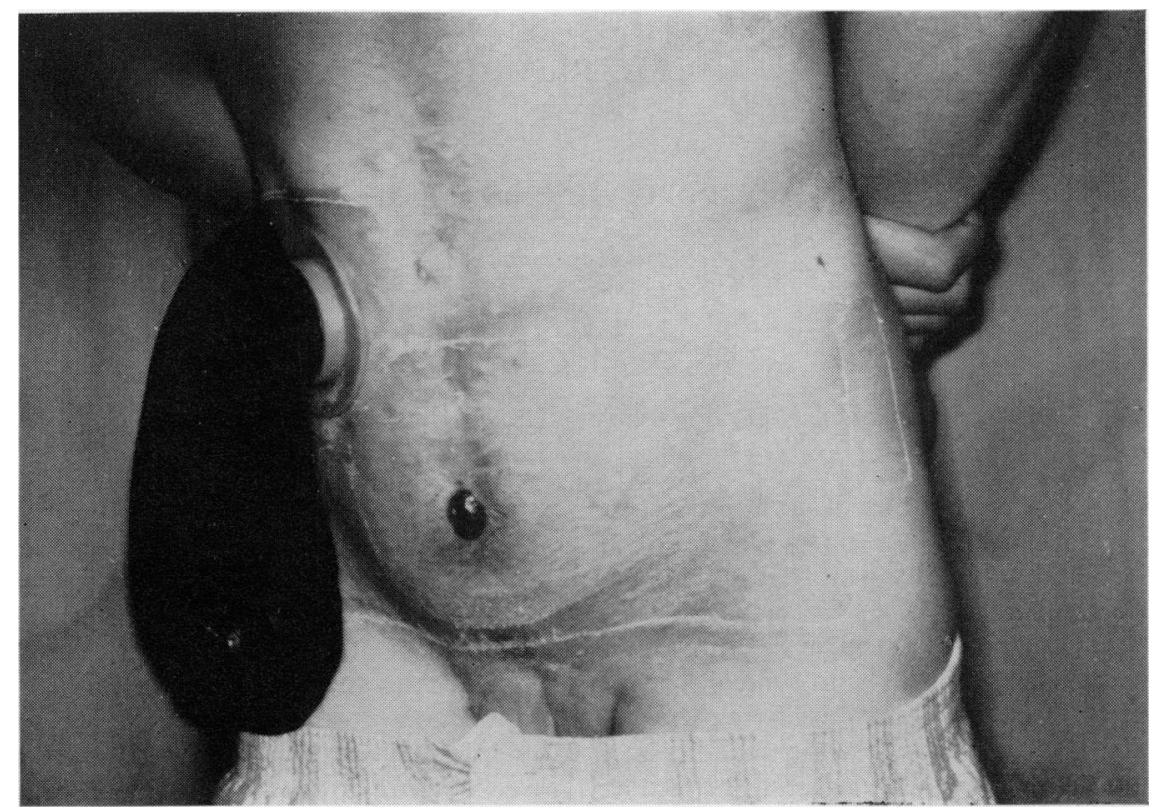

FIG. 2.

\section{Discussion}

Satisfactory management of an ileostomy requires that the appliance is maintained firmly in position round the projecting stoma. In the early postoperative period leakage of contents often occurs, especially in the thin, recumbent patient. Repeated applications of disposable adhesive bags on to constantly moist skin around the stoma may produce severe skin excoriation.

The Koenig-Rutzen ileostomy appliance consists of a flat bag that fits on to a flanged circular disc which has a central hole for the stoma. Supported by a light belt, which is essential, the disc if necessary can also be cemented to the skin with a variety of rubber adhesives. Unfortunately these are all viscous, and possess the property called 'creep'. There is always a tendency for the disc to slide and leakage frequently occurs. Sometimes, as in the second patient, pressure by the disc on the projecting stoma can cause necrosis and produce a fistula.

Isobutyl cyanoacrylate is a non-viscous powerful adhesive, which may be of value in fixing an appliance to the skin. In the two patients reported the adhesive was used for this purpose and eliminated leakage of ileal contents. In both cases the skin was first patch tested to exclude possible skin sensitivity.

Provided an ileostomy has been correctly fashioned, its eventual management with an appliance is usually satisfactory and only occasionally is a viscous adhesive needed. During the early post- operative period, however, leakage of contents is almost inevitable and the necessary repeated application of disposable adhesive bags may lead to severe skin excoriation. The routine use of isobutyl cyanoacrylate to fix the disc of an ileostomy appliance during the initial postoperative period might be of use in reducing skin excoriation. The encouraging results of using the adhesive in the two patients reported suggests that isobutyl is of value when dealing with a difficult ileostomy or ileal conduit.

\section{Acknowledgments}

I wish to thank Professor Harold Ellis and Mr Robert Cox for permission to report these two patients, and also Ethicon Ltd., of Edinburgh for generous supplies of Isobutyl Cyanoacrylate.

\section{References}

Brooke, B.N. (1952) The management of an ileostomy including its complications. Lancet, ii, 102.

Hale, J.E. \& Ellis, H. (1968) Isobutyl cyanoacrylate as a tissue adhesive. An experimental study. British Journal of Surgery, 55, 850.

Healey, J.E., JR, Clark, R.L., Gallagher, H.S., O'Neill, P. \& Sheena, K.S. (1962) Non-suture repair of blood vessels. Annals of Surgery, 155, 817.

Matsumoto, T., Hardaway, R.M., Heisterkamp, C.A., PANI, K.C. \& LeONARD, F. (1967) Higher homologous cyanoacrylate tissue adhesives in surgery of internal organs. Archives of Surgery, 94, 861.

VASKo, J.S. \& BROCKMAN, S.K. (1965) Clinical and experimental experiences with plastic adhesives. Annals of Surgery, 162, 123. 